\title{
Cues must increase smoking behaviour to be clinically relevant
}

\author{
Kenneth Alan. Perkins
}

\section{Keywords}

craving; cue reactivity; smoking behaviour; drug-seeking behaviour; relapse; dependence; drug reinforcement; environmental cues

I appreciate the thoughtful reactions to my "for debate" article by these distinguished researchers and will focus my reply on their key points [1]. However, much of what Tiffany and Shiffman stated will get little response from me here, because they largely agreed with a number of my points or opposed arguments I do not make [2,3]. Regarding our areas of agreement, both: noted the likely association between drug-related cues and smoking behaviour but agreed that the association between cue-induced craving and smoking behaviour is weak; commented on the lack of assessment of smoking behaviour in response to cues; and discussed the likelihood that more complex study designs may be necessary to show an association between cue reactivity measures and relapse risk, as I note at the end of my paper. Yet, both also opposed the idea that cue reactivity procedures and research on the concept of craving should now be abandoned, proposals my piece never made.

To reiterate, my article does not criticize the study of craving or call for "abandoning this line of research". Some of the comments by Tiffany appear to overgeneralize from my specific criticisms about cue-induced craving to craving in general. Although I stated that abstinence-induced craving has, but cue-induced craving has not, demonstrated clinical validity, I did not question the basic rationale behind the cue reactivity procedure. Environmental stimuli associated with smoking almost certainly contribute to smoking relapse, as my piece acknowledges, although evidence for Shiffman's implicit claim of a causal role for cue-induced craving is unclear.

Rather, my main criticism was of the over-reliance on self-reported craving as the primary, and often only, dependent measure in response to cue administration, when self-reported craving in response to cues is known to be poorly associated with smoking behaviour in the short term and relapse risk in the long term [4]. Similar criticisms can be levelled at physiological responses in cue reactivity studies [5]. By contrast, near the end of their comments, both Shiffman and Tiffany place more emphasis on the idea that tweaking the experimental conditions, or the independent variables, in the right way is likely to ultimately demonstrate the predictive validity of cue-induced self-reported craving. They say little about the need for better dependent measures more closely related to smoking persistence, such as behavioural indices of smoking reinforcement [6,7]. The attention paid by the cue reactivity field to self-reported craving versus smoking behaviour seems to be in inverse proportion to their link to dependence. As I stated, dependence and the health risks of smoking are determined by the persistence of smoking behaviour, not craving [8], and a factor that influences smoking behaviour but not craving will be easier to relate to dependence than a factor that influences craving but not smoking behaviour. Elsewhere,

Correspondence to: Kenneth A. Perkins, Western Psychiatric Institute \& Clinic, University of Pittsburgh School of Medicine, 3811 O’Hara Street, Pittsburgh, PA 15213, USA; perkinska@upmc.edu. 
Tiffany [4] has observed that "reactivity measures other than craving have been selected more on the basis of convenience...". That criticism appears to apply to self-reported craving as well.

As Shoaib nicely outlines [9], the animal model most relevant to this discussion, the reinstatement procedure, generally has the dependent measure correct, in my view, by focusing on "nicotine-seeking" behaviour, despite the model's imperfect conformity with human smoking persistence [10]. Shoaib goes further to suggest that studying the role of the anterior cingulate in the reinstatement procedure may elucidate mechanisms responsible for smoking cue reactivity. Such research is likely to be important. However, there is little reason to think that advances in our understanding of cue-induced reinstatement of animal drug-seeking behaviour will be relevant to human cue reactivity research until the latter begins to routinely study drug-seeking behaviour. Because the correlation of self-reported craving with smoking behaviour has been estimated at only 0.24 [4], it seems unlikely that the mechanisms underlying drug-seeking behaviour will have any greater association with the mechanisms underlying self-reported craving. In other words, elucidating influences on human drug-taking behaviour, rather than on self-reported craving, should be the criterion upon which animal models of substance abuse processes are based.

Finally, both Tiffany and Shiffman plead that cue reactivity research should continue, as do I as long as the results of this research clearly improve our understanding of smoking persistence (especially relapse risk) or other important indices of dependence [e.g., 11]. Tiffany views this standard as "narrow", but what other indices determine the health risks from smoking? He supposes that I "...might recommend that we turn our back on cuereactivity studies, particularly those that focus on craving" if cue-induced craving fails to show any association with this standard. In response, I would argue that any line of research that repeatedly fails to demonstrate a relationship between a measure and the disorder of interest does not aid public health or warrant priority for further study, given finite resources to support research. Scientists should follow the data wherever they lead. If the data lead to a dead end, it is pointless to persist on the same course and not change direction. Otherwise, it is not evidence but rather faith that is guiding the research.

\section{Acknowledgments}

Declaration of interest: Kenneth Perkins is supported NIH grants DA19478 and P50 DA/CA84718. He has consulted with GlaxoSmithKline regarding the development of smoking cessation medications.

\section{References}

1. Perkins KA. Does Smoking Cue-Induced Craving Tell Us Anything Important About Nicotine Dependence? Addiction. in press.

2. Tiffany ST, Wray J. The Continuing Conundrum of Craving. Addiction. in press.

3. Shiffman S. Responses to smoking cues are relevant to smoking and relapse. Addiction. in press.

4. Tiffany, ST.; Warthen, MW.; Goedeker, KC. The functional significance of craving in nicotine dependence. In: Bevins, RA.; Caggiula, AR., editors. The motivational impact of nicotine and its role in tobacco use. Springer-Verlag; New York: 2009. p. 171-97.

5. Sayette MA, Shiffman S, Tiffany ST, Niaura RS, Martin CS, Shadel WG. The measurement of drug craving. Addiction. 2000; 95(suppl 2):S189-S210. [PubMed: 11002914]

6. Perkins KA, Epstein LH, Grobe J, Fonte C. Tobacco abstinence, smoking cues, and the reinforcing value of smoking. Pharmacol Biochem Behav. 1994; 47:107-12. [PubMed: 8115411]

7. Droungas A, Ehrman RN, Childress AR, O'Brien CP. Effect of smoking cues and cigarette availability on craving and smoking behavior. Addict Behav. 1995; 20:657-73. [PubMed: 8712062]

8. American Psychiatric Association. Diagnostic and statistical manual of mental disorders. 4th ed. APA; Washington, DC: 1994. 
9. Shoaib M. Cue-reactivity in rodents - how predictable? Addiction. in press.

10. Epstein DH, Preston KL, Stewart J, Shaham Y. Toward a model of drug relapse: an assessment of the validity of the reinstatement procedure. Psychopharmacol. 2006; 189:1-16.

11. Baker TB, Piper ME, McCarthy DE, Bolt DM, Smith SS, Kim S-Y, et al. Time to first cigarette in the morning as an index of ability to quit smoking: implications for nicotine dependence. Nic Tob Res. 2007; 9(suppl. 4):S555-70. 